УДК 159.922 .4 : 930.85

DOI $10.21661 / \mathrm{r}-467360$

\title{
А.Н. Кутейников
}

\section{РЕКОНСТРУКЦИЯ ПСИХОЛОГИЧЕСКОГО ПОРТРЕТА ДРЕВНИХ ГРЕКОВ КЛАССИЧЕСКОГО ПЕРИОДА}

Аннотация: в статье обсуждается зависимость психологического склада людей от условий жизни в соответствующую эпоху. Рассматривается доминирование конкретных черт характера и ценностных ориентаций у древних греков классического периода. Описывается мировоззрение и ментальность греков в указанный период. Представление о коллективной ответственности. Парис как собирательный образ древнего грека. Трудолюбие. Культ красоты обнаженного тела. Постепенный отказ от жертвоприношений. Терпимость к гомосексуализму. Гуманное отношение к рабам. Интеллектуальная соревновательность.

Ключевые слова: древние греки, психологический портрет, ментальность, возможность выбора, воинственность, жертвоприномения, инфантицид, чувственность, свободомыслие.

\section{A.N. Kuteynikov}

\section{RECONSTRUCTION OF THE ANCIENT GREEKS' PSYCHOLOGICAL PORTRAIT IN THE CLASSIC PERIOD}

Abstract: the article discusses the dependence of the psychological structure of the living on conditions of people in the appropriate age; considers the dominance of specific character traits and values of the ancient Greeks of the classical period; describes the worldview and mentality of the Greeks in the specified period. The concept of collective responsibility. Paris as a collective image of the ancient Greeks. Respect for labour. The cult of beauty of the naked body. Gradual disclaimer out the offerings. Tolerance of homosexuality. The humane attitude to slaves. Intelligent competitiveness. 
Keywords: the ancient Greeks, psychological portrait, mentality, possibility of choice, belligerence, sacrificing, infanticide, sensuality, freethinking.

В исторической психологии очень трудно провести эксперимент. Например, как выглядел бы идеальный эксперимент по составлению психологического портрета древних греков? Для этого нам надо сесть в машину времени, слетать в Древнюю Грецию, найти достаточно репрезентативную выборку древних греков, войти с ними контакт, предложить им пройти психологическое тестирование, например, при помощи часто применяющегося в подобных исследованиях теста $16 \mathrm{PF}$ (разумеется, предварительно переведя текст опросника на древнегреческий язык). После этого остается провести обработку результатов тестирования и составить усредненный психологический профиль испытуемых. Разумеется, это само по себе является нереальной задачей. Причем, начиная с самого первого ее этапа.

Тем не менее, специалистами по исторической психологии подобные задачи, связанные с описанием личности людей определенной эпохи, все же решаются. Правда, для этого им приходится работать не с реальными людьми, а с продуктами их деятельности. Например, анализируя произведения литературы и культуры людей указанных эпох, в частности, их мифологию. Однако, это еще не все. Здесь надо определиться с временными границами нужной исследователю эпохи. Например, древние греки - это понятие неоднородное. Были греки так называемого архаического периода; были более поздние дорийские греки, представлявшие период, называемый в античной истории классическим. Были также говорившие по-гречески македонцы, которые являлись в этническом смысле не совсем греками (судя по всему, это был смешанный этнос греков и предков албанцев). Отдельно следует упомянуть о жителях эллинистических государств, образовавшихся после распада империи Александра Македонского. Жители указанных стран были грекоязычными (по крайней мере, это можно сказать об их элите), носили греческие имена, ментально они были привержены греческой культуре и религии, но этнически это были в значительной степени ассимилированные жители завоеванных Александром варварских государств. 
Итак, на основе анализа литературных источников можно дать достаточно развернутый психологический портрет представителей определенной исторической эпохи. Например, А.Д. Барской посредством анализа «Илиады» и «Одиссеи» составлено описание психического склада древнего грека гомеровской эпохи. Указанная автор выделяет в качестве ведущих следующие свойства психики:

1. Преобладание наглядно-образного мышления над абстрактно-логическим.

2. Недостаточная развитость самосознания по сравнению с таковым у современного человека (но Барская отмечает, что в их самосознании уже присутствует внутренний диалог).

3. Недостаточность волевой регуляции поведения.

4. В гомеровских текстах значительная часть мыслей, желаний, чувств, действий или внешних событий, которые современный человек воспринял бы как случайные, приписываются божественному вмешательству.

5. Но, тем не менее, автор уже видит у гомеровских греков способность оценивать ближайшие последствия своих действий (то, что в психологии называется сформированностью целеполагания).

Когда мы устремим свой взор на греков классического периода, то количество письменных источников увеличивается, и мы можем уже составить более развернутый психологический портрет рассматриваемого коллективного объекта исследования. При этом следует считать, что ментальность греков классического периода - это дальнейшее развитие ментальности гомеровских греков, что между ними есть прямая преемственность. Таким образом, описанные Барской особенности психики должны присутствовать и у более поздних представителей Эллады.

Итак, какие же особенности мотивационной и эмоциональной сфер, какие ценностные ориентации, да и вообще какие особенности психического склада были характерны для греков анализируемого нами периода? 
Как греки объясняли тот факт, что в мире чаще всего отсутствует справедливость? Во-первых, они верили, что потомок отвечает за грехи предков. Именно такую мысль доносит Эсхил в своей трилогии «Орестея». Содержание этой трилогии - судьба рода Атридов, героев Троянской войны. Можно конечно предположить, что это точка зрения только Эсхила, но если бы греки не были с ним согласны, то трагедии Эсхила не пользовались бы такой популярностью! Кстати, эта концепция изначально защищена от логических противоречий. Если страдает потомок, то грекам все становится понятно - это предок преступил какие-то нравственные законы. А если человек умирает бездетным - то никакого противоречия тоже нет, это тоже такой вид наказания за что-то со стороны богов. Ведь у каждого грека должны быть какие-то грехи, надо только повнимательнее проанализировать его жизнь.

Во-вторых, возможен и такой вариант, что за грехи отдельных представителей социума страдает весь их полис. Например, царь Эдип убил своего отца Лая. В наказание за это преступление боги послали на Фивы моровую язву и через оракула объявили, что язва не прекратится, пока из города не будет изгнан отцеубийца. Но вся проблема была в том, что фиванцы не знали, кто является отцеубийцей. Не знал этого и их царь Эдип: он лишь позднее выяснил, что когда-то убитый им в случайной ссоре человек был его биологическим отцом. И лишь после того, как Эдип отказывается от царского статуса (по своей собственной воле!) и уходит нищенствовать, эпидемия в городе прекращается. Именно так описывается эта трагическая история у и Гомера, и у Гесиода, и у Эсхила.

Для древних греков характерно эмоциональное восприятие мира и чувственность. Яркой иллюстрацией к этому здесь может служить описанный рядом древних авторов «Суд Париса». Итак, к Парису подошли три богини: Гера, Афина и Афродита - и попросили его выступить арбитром в споре: кто из них прекраснее. Вслед за этим они начали пытаться его подкупить, каждая в свою пользу. Гера обещала ему господство над Азией, Афина - победы и военную славу, а Афродита - обладание прекраснейшей из женщин. Что выбрал Парис? 
То, что он считал наиболее ценным: он принял предложение обладать прекрасной женщиной. Ей стала нимфа Энона.

Парис был олицетворением красоты и изнеженности, но в то же время он был способным на осуществление самых рискованных замыслов. Именно Парис, как это описано в продолжении мифа украл Елену Прекрасную (разумеется, бросив Энону), чем и спровоцировал начало Троянской войны. Он принял также и участие в сражениях этой войны, во время одного из них он погиб. Разумеется, образ Париса - это собирательный образ древнего грека: изнеженного и эмоционального, но воинственного, рискованного, азартного и даже в некоторой степени адреналинозависимого. И все три мотива были актуальны для греческих мужчин: и желание овладеть Азией (именно туда направлялся один из потоков греческой колонизации), и победа над врагами (стремление ставшее особенно актуальным после постоянных вторжений персов), и желание иметь рядом с собой прекрасную женщину.

О культе воинственности греков говорит и следующее предание. На одном из поэтических состязаний встретились Гомер и Гесиод. Оба претендовали на право именоваться лучшим поэтом, и они должны были продекламировать свои лучшие оды. Судья присудил победу Гесиоду, так как последний призывал к миру и земледельческому труду. А Гомер описывал более ужасное занятие войну. Но все присутствующие возмутились, и, не смотря на официальную победу Гесиода, вслед за этим толпа провозгласила Гомера величайшим поэтом.

В мифе о Парисе мы видим еще одно явление, судя по всему впервые появившееся только в Древней Греции - возможность делать выбор. Это было очень важно для греков. Для сравнения можно рассмотреть такую ситуацию: допустим, в древнем Шумере царь какого-то города издает указ: всех мобилизовать на строительство некого нового канала. И назавтра все горожане должны вне зависимости от своих способностей, состояния здоровья, недоделанной работы бросить все свои дела и идти рыть канал. А в Древней Греции подобная ситуация, пожалуй, просто и не могла бы возникнуть. Там человек (по крайней мере, свободный человек) мог в большей мере распоряжаться собственной судьбой. 
Для греков была характерна такая черта как трудолюбие. К сожалению, принято воспринимать всех древних греков как сибаритов. Но есть все основания полагать, что этот образ греков не соответствует действительности. Ф.Ф. Зелинский возмущенно заявляет по этому поводу: «Кем-то когда-то было пущено в оборот положение, будто древние греки пренебрежительно и презрительно относились к физическому труду; и с тех пор эта нелепость безвозбранно гуляет по страницам руководств и изложений, черпающих свои материалы из вторых и десятых рук». Зелинский приводит примеры из греческой поэзии и мифологии, свидетельствующие, что греки почитали труд и уважали тех, кто может создать что-либо своим собственными руками. Например, автор ссылается на упомянутого выше Гесиода, создавшего в поэме «Труды и дни» настоящий гимн труду: «Труд никакой не позорен, позорно одно лишь безделье ...».

Кстати, современные археологические данные не подтверждают мнение о том, что жители Сибароса (города, в котором согласно легенде жили сибариты) были богаче других греков, или что они отвергали физический труд.

Следующая черта древних греков - культ красоты обнаженного тела. Для обозначения идеала мужского совершенства у греков существовала формула «прекрасен телом и душой». И действительно, у них господствовал культ красоты обнаженного мускулистого спортивного мужского тела. Ученики в гимнасии должны были заниматься спортом и изучать науки обнаженными (разумеется, посещать гимнасии могли только юноши). В обнаженном виде выступали греки и на состязаниях в Олимпийских играх. Кстати, все статуи того периода демонстрируют прежде всего мускулистые и красивые тела людей: Лаокоон, Гермес Праксителя, Аполлон Бельведерский.

Для подчеркивания значимости этого стиля поведения, можно сравнить представления древних греков и древних евреев. У последних был совершенно противоположный императив. Иудей не должен был обнажать свое тело! В легенде о Ное, обнажившим во сне свое тело, и его сыне Хаме, посмеявшимся над отцом, осуждается не только поступок Хама, но и запрещается сама возможность обнажения тела. 
Греки положительно относились не только к обнажению мужского тела, они приемлемо относились и к обнаженнию женского тела. Множество древнегреческих статуй подчеркивают именно не эротизм, а красоту обнаженного женского тела: Венера Каллипига, Венера Милосская, Афродита Книдская, Хариты. И опять же отношение греков выражается в мифе. Сюжет про Гермеса, укравшего у купающихся собственных матери и сестер одежду, трактует его поступок не как предосудительное поведение, а как шалость, как мелкое хулиганство, над которым стоит посмеяться и лишь развести руками.

Для мироощущения древних греков очень большое значение имела возможность соревновательности в спорте. Олимпийские игры - это величайшее изобретение древних греков. Именно в них, имевших изначально религиозный смысл, нашли свое максимальное выражение культ героев и культ здорового тела. Ни одна другая цивилизация древности даже не пыталась создать что-нибудь подобное. И только гладиаторские бои римлян могут считаться жалким подобием этих великих соревнований.

Дополнительно следует отметить, что место проведения Олимпийских игр это гора, являющаяся с точки зрения греков обиталищем богов. Можно ли представить себе, чтобы древние евреи проводили какие-то подобные массовые мероприятия, допустим, на Синайской горе? Отвечая на этот вопрос, можно предположить, что с точки зрения греков боги были более открытыми для диалога с людьми, хотя и через посредников-оракулов. А еврейский Бог все же был менее доступен для своих последователей.

Отсутствие массовых человеческих жертвоприношений - еще одна характерная черта древней Греции (правда, процедура казни преступника тоже преподносилась как жертвопреношение). Есть основания предполагать, что это было одним из факторов развития личности вследствие устранения страха перед завтрашним днем и причиной развития свободомыслия у греков. Ведь кого жрецы скорее принесут в жертву? Того, кто мыслит не так как все остальные, кто имеет на все свой собственный взгляд, кто, как это сказано в одном из романов братьев Стругацких, «захотел странного». Этим эллины выгодно отличались от 
египтян и шумерцев, устраивавших (до III тысячелетия до н.э.) вместе с умершим правителем массовые погребения его слуг. Лишь на Крите современными археологами были обнаружены следы группового принесения людей в жертву. Но и этот факт не всегда правильно интерпретируется. Известно, что на Крите в минойскую эпоху жило как раз население негреческого происхождения, и только после победы греков над ними и ассимиляции минойцев групповые жертвоприношения постепенно прекратились и там.

Одиночные жертвоприношения, к сожалению, просуществовали у греков еще некоторое время. Когда они окончательно исчезли, точную дату назвать трудно. Но можно сослаться на мнение О. Колобовой и В. Иванова отмечавших, что «... человеческая кровь прекратила литься на алтари Эллады лишь к четвертому веку до н.э., а быть может, и позже».

Широко известны мифы греков, которые описывают отрицательное отношение к человеческим жертвам. Например, это миф о Персее, спасшем предназначенную к жертвоприношению Андромеду. Учитывая, что Персей - грек, а Андромеда - дочь эфиопского царя, можно сделать вывод, что, во-первых, некоторые греки уже в архаический период выступали против человеческих жертв (и тем самым они не боялись выступать против воли богов!), а во-вторых, что среди варваров этот обычай был более распространен.

Неприятие эллинами человеческих жертвоприношений отражено и в мифе о Ифигении. Содержание мифа незначительно различается в разных источниках, однако во всех вариантах просматривается следующее общее содержание. Оракул возвестил Агамемнону, отцу Ифигении, что необходимо было принести дочь в жертву, чтобы боги помогли ахейцам одержать победу над троянцами. Агамемнон заманил ее в лагерь, солгав, что оракул будто бы повелел ее отдать замуж за Ахилла, а сам распорядился начать подготовку к жертвоприношению. Но тут возмутился Ахилл, он не хотел быть косвенным виновником смерти девушки. В результате вместо Ифигении в жертву была принесена коза, а сама девушка была увезена Ахиллом в Тавриду, где она стала царицей тавров. Но после этого она 
сама была вынуждена участвовать в обрядах человеческих жертвоприношений, ибо у тавров этот обычай имел более широкое распространение, нежели у греков.

В данном мифе греки зашифровали три принципа:

1. Запрет на принесение человеческих жертв.

2. Принесение человеческих жертв - это удел варваров.

3. Вместо людей можно приносить в жертву животных.

Подобный же мотив можно уловить в библейской истории с запретом Аврааму приносить в жертву своего сына Исаака (вместо него жертвой стало как и у греков домашнее животное, баран). Тот же сюжет мы видим в Коране, где Ибрагим не стал убивать своего сына, а вместо него принес другую жертву (в тексте Корана не сказано какую, но согласно устной традиции ислама, это был тоже баран). Судя по всему, именно отказ от человеческих жертвоприношений позволил указанным трем цивилизациям каждой в свое время совершить рывок в культурном развитии.

Однако оставался еще один вариант жертовоприношения - принесение себя самого в жертву богам, что можно воспринимать как своеобразный суррогат альтруизма. В современном мире это вопринимается как вариант аддиктивного поведения и пойти на такой шаг люди способны чаще всего либо в состоянии депрессии, либо при неадекватной реакции на стресс, либо в ситуации безвыходности. Прекращение альтруистического принесения себя в жертву греками тесно связано с осознанием ими ценности любой человеческой жизни. И это тоже явилось ступенькой на пути дальнейшего духовного развития греков.

Следующей чертой древних греков можно назвать терпимость к гомосексуализму. Чем можно объяснить это социальное явление? Одной причины выделить невозможно, это было, судя по всему, полифакторное явление.

Одной из предпосылок было то, что мужчины в Древней Греции поздно вступали в брак. Для того, чтобы быть успешным женихом, нужно обладать собственностью и пользоваться уважением сограждан. А это было реально только в уже достаточно зрелом возрасте. Кстати, если следовать Пифагору, то молодым 
человеком следовало считать людей в возрасте от 20 до 40 лет, а человек в расцвете сил - это диапазон от 40 до 60 лет.

Еще одна причина - нехватка продуктов питания и перенаселенность. По свидетельству Аристотеля, один критский законодатель, чтобы его соотечественники не рожали много детей, ввел сожительство мужчин с мужчинами. Таким образом, гомосексуализм выполнял функцию средства ограничения рождаемости и борьбы с перенаселением в условиях ограниченности ресурсов.

Косвенным подтверждением того тезиса, что греки стремились иметь меньше детей, можно назвать распространенность детоубийств новорожденных детей собственными родителями. По мнению Ллойда де Моза, инфантицид был достаточно широко распространен среди древних греков. Проблема детоубийства отражена и в греческой мифологии. Например, Эдип еще в младенчестве по приказу родного отца должен был быть отнесен в лес и брошен на съедение волкам.

Известен и обычай в Спарте отказывать слабому или больному новорожденному ребенку в праве на жизнь. У спартанцев подобное решение принимал уже не отец ребенка, а совет старейшин. Конечно, это избавляло отца от чувства вины, а у старейшин способствовало распылению индивидуальной ответственности, но это не способствовало прогрессу общества. Вполне возможно, что если бы спартанцы узнали, что через две с небольшим тысячи лет ценность людей будет оцениваться не только по их физической силе и здоровью, но и по уровню их умственных способностей, они бы удивились.

В подтверждение тезиса о нежелательности детей и распространенности инфантицида можно вспомнить также утверждение Полибия (жившего во II веке до н.э.): «Эллада обезлюдела, потому что никто не хочет жениться, а если женятся, то избавляются от детей».

Возвращаясь к проблеме гомосексуализма в Древней Греции, надо отметить, что не везде отношение к нему было терпимым. Официальная институциализация этого явления существовала только в Спарте. В Афинах же, например, существовал закон, лишавший права выступать в суде, быть избранным в 
архонты, быть жрецом или должностным лицом тех людей, кто «отдавал своё тело в разврат» (то есть, речь шла о «поражении в правах» пассивных гомосексуалистов). А сексуальное посягательство на свободнорожденного мальчика вообще каралось смертью. Тем не менее, не стоит по прошествии тысячелетий пытаться дать нравственную оценку этому явлению. Надо просто признать, что оно было. И если бы у греков не было такого «опыта», то может, им и не удалось бы создать свою оригинальную чувственную и полную эстетизма культуру.

Можно ли чем-либо еще кроме нехватки продовольственных ресурсов объяснить причину распространенности инвертированного поведения у греков?

Можно в качестве возможного объяснения привести точку зрения 3. Фрейда, который предполагал, что причина подобного поведения заключается в том, что у молодых греков учителями и воспитателями были исключительно мужчины среднего возраста. Хотя, здесь не понятна сама причинная связь: почему отношения зрелого педагога и юноши должны были обязательно приводить к гомосексуальным связям.

Поэтому автор настоящей статьи предлагает придерживаться иной точки зрения. Известно, что у греков широкое распространение получили фармакологические средства растительного происхождения, относящиеся к алкалоидному ряду. При этом часть из них являлись легкими наркотиками. Данной теме посвящена монография американского специалиста Д. Хиллмана.

А как подобные наркотики действуют на сексуальное поведение? Условно можно выделить три стадии подобного влияния (описанные ниже закономерности касаются только растительных наркотиков). На первой стадии происходит раскрепощение, и у принимающих наркотик увеличивается частота половых актов. На второй - может наблюдаться смещение полового поведения на нетрадиционные объекты, можно сказать, что для человека «сексуальное экспериментирование» становится навязчивой потребностью. Именно в этом автор статьи и предлагает видеть причины распространенности нетрадиционных сексуальных отношений у греков. На третьей стадии употребление наркотиков может ухудшать качество спермы и вести к эректильной дисфункции. 
Впоследствии греки постепенно отказывались от инвертированного поведения. Скорее всего, здесь сыграло роль как исчезновение опасности перенаселенности и угрозы постоянной нехватки продовольствия (с середины VIII века днэ началось масштабное расселение древних греков по берегам Средиземноморья), так и общий духовный прогресс. Судя по жизнеописаниям римских императоров, то в имперскую эпоху к гомосексуализму больше тяготели уже римляне. Об этом же говорит и Иоанн Богослов в своем «Откровении ...».

Рабовладение, насколько мы можем предположить, не оставило глубокой нравственной деформации на гуманном менталитете греков классической эпохи. С целью их частичной «реабилитации», следует отметить следующие два момента. Во-первых, в ту эпоху рабовладение было единственным способом развития производительных сил, т.е. у греков просто не было другого выбора. И любой, даже и более развитый в культурном отношении этнос был бы обречен создать рабовладельческий строй. Во-вторых, отношение к рабам у греков было более гуманным, чем это гласят устоявшиеся стереотипы. Ведь раб представлял собой говорящий инструмент, и портить свои инструменты - это расточительно и глупо. Очень часто отношение у греков к домашнему рабу было примерно такое же как к очень полезному в хозяйстве домашнему животному - собаке. О положении рабов в Афинах говорят следующие факты (хотя, в разных городах это отношение было различным).

1. Некоторые из рабов могли скопить себе достаточно крупные состояния.

2. В Афинах никогда, насколько нам известно, не происходило восстаний рабов.

3. Ксенофонт пишет о необычайной «дерзости» афинских рабов: они не уступали дороги гражданам, и их нельзя было бить из боязни ударить вместо раба гражданина, так как последний в Афинах внешне не отличался от первого.

К сожалению, после походов Александра на Восток и завоевания деспотичных и отсталых в культурном отношении государств, отношение греков к рабам изменилось: у рабовладельцев часто возникало чувство безнаказанности и игнорирование моральных норм. 
Следующая характерная черта древних греков - это стремление к интеллектуальной соревновательности. У эллинов были развиты традиции публичного философского спора. Причем, когда шел научный диспут, чинопочитание можно было и не соблюдать. Ученик мог спорить с учителем, и, если он спорил аргументировано, то он удостаивался похвалы. Известен следующий случай: еще молодой Платон во время своей первой встречи с великим Сократом принялся с ним спорить. После окончания диспута Сократ решил взять Платона к себе в ученики. А с самим Платоном через много лет постоянно спорил уже его собственный ученик - Аристотель, провозгласивший ставший символическим лозунг: «Платон мне друг, но истина дороже».

Возможны ли были подобные традиции интеллектуального спора, допустим, в Древнем Египте? Разумеется, нет. Знания очень ценились египетскими жрецами, но известно, что большая часть фараонов была под влиянием жреческой касты и их культов. А жрецы, как умелые кукловоды, манипулируя мнением как народа, так и фараона, постоянно плели свои интриги. Сама ситуация публичного столкновения мнений была бы просто опасна для веры в сакральность жрецов.

Невозможно представить традиции публичного интеллектуального спора и в древнем Китае. Там просто не принято было отличаться в чем-то от других. Кстати, эта черта характера - стремление не выделяться на фоне окружающих в значительной степени сохранилась у китайцев и по сей день. Были, конечно, и в Китае свои великие философы. Но они обсуждали чаще не научные проблемы, как это было принято у древних греков, а морально-этические.

Еще одна черта древних греков - это значимость досуга. Досуг воспринимался как такая же возвышенная сфера жизнедеятельности, как война или политика. Было модно посещать театр, вести философские диспуты, принимать участие в пирах. А на пиру было принято наслаждаться музыкой, пением и вести интеллектуальные беседы. Именно благодаря такому типу времяпровождения греческая элита правильно распорядилась свободным временем и смогла заложить предпосылки современной европейской культуры и научной картины мира. 
И, можно предположить, если бы Греция не смогла передать свой интеллектуальный, нравственный и культурный багаж последующим цивилизациям, то на весь путь исторического прогресса человечеству понадобилось бы значительно больше времени.

Таким образом, мы можем сделать вывод, что в классическую эпоху для греков были характерны следующие личностные черты и паттерны мировоззрения:

1. Принятие принципа коллективной ответственности и недостаточно выраженная (по сравнению с современными людьми) индивидуальность.

2. Осознание возможности делать выбор, пусть и в определенных рамках, признавалось как само собой разумеющееся явление. Но вместе с тем это сочеталось с верой в фатальность событий и невозможностью противостоять воле богов.

3. Эмоциональное восприятие мира и чувственность, иногда доходившее до экзальтированности и эмоциональной неуравновешенности.

4. Воинственность, адреналинозависимость.

5. Трудолюбие.

6. Культ красоты обнаженного тела.

7. Культ олимпийских игр, и как следствие, азартность, соревновательность, с одной стороны, и мотивация к спорту и здоровому образу жизни (так, как его понимали сами греки), с другой стороны.

8. Вследствие постепенного отказа от человеческих жертвоприношений снижение страха перед завтрашним днем, осознание ценности собственной жизни, возрастание значимости альтруизма.

9. Толерантность к гомосексуализму.

10. Относительно гуманное отношение к рабам (по сравнению с периодами эллинизма и Римской империи).

11. Свободомыслие и выработка традиций интеллектуального спора (по сравнению с представителями других окружающих народов).

\section{Список литературы}


1. Барская А.Д. Психолого-историческая реконструкция особенностей психики гомеровского человека: Дисс. ... канд. психол. наук / А.Д. Барская. - 1998. $207 \mathrm{c}$.

2. Воеводский Л.Ф. Каннибализм в греческих мифах. Опыт по истории развития нравственности / Л.Ф. Воеводский. - СПб, 2011.

3. ДеМоз Л. Психоистория. - Ростов/Д.: «Феникс», 2010.

4. Дюпуи Э. Проституция в древности. - М.: Терра, 2010.

5. Зелинский Ф.Ф. История античных религий: В 3 т. - СПб.: Алетейя, 2015.

6. Ивик О. История человеческих жертвоприношений. - М.: Ломоносов, 2010. $-64 \mathrm{c}$.

7. Кутейников А.Н. История психологии: конспект лекций / А.Н. Кутейников. - СПб.: Изд-во СПбГУ, 2008.

8. Hillman D.C.A., The chemical muse: drug use and the roots of Western civilization - New York, Pablishing St. Martin's Press, 2008.

\section{References}

1. Barskaja, A.D. Psycho-Historical Reconstruction of Peculiarities of the Psyche of the Homeric Man. Dissertation of candidate of psychological Sciences M, 1998.

2. Voyevodskiy L.F. Cannibalism in Greek Myths. Experience the History of the Development of Morality. St. Petersburg, 2011.

3. DeMause L. Psychohistory. Rostov-on-Don, Phoenix, 2010.

4. Dupuis, E. Prostitution in Antiquity. M, Terra, 2010.

5. Zielinski, T.F. History of Ancient Religions. Rostov/D, Phoenix, 2010.

6. Ivik O. the History of Human Sacrifice. M, publishing house of the «LomonoSov», 2010.

7. Kuteynikov A.N. History of psychology: lecture notes. St. Petersburg, publishing house of St. Petersburg state University, 2008.

8. Hillman D.C.A., The chemical muse: drug use and the roots of Western civilization - New York, Pablishing St. Martin's Press, 2008. 
Кутейников Алексей Николаевич - канд. психол. наук, доцент факультета социальных технологий Северо-Западного института управления (филиала) ФГБОУ ВО «Российская академия народного хозяйства и государственной службы при Президенте РФ», Россия, Санкт-Петербург.

Kuteynikov Alexey Nikolaevich - candidate of psychological sciences, associate professor of Social Technologies Faculty at the North-West Institute of the Russian Presidential Academy of National Economy and Public Administration, Russia, SaintPetersburg. 